\title{
Applications of Nuclear Techniques and Microscopy to Surface Analysis of Materials
}

\author{
José A. R. Pacheco de Carvalho, ${ }^{*}$ and António D. Reis ${ }^{*}$ \\ * Remote Detection Unit, Department of Physics, University of Beira Interior, Rua Marquês \\ d'Ávila e Bolama, 6201-001 Covilhã, Portugal
}

The importance of surface analysis of materials has been increasing. The available techniques are complementary. Nuclear techniques, which are non-destructive, provide analysis for a few microns near the surface. Using low energy ion beams of a few $\mathrm{MeV}$, applications have been made to several areas [1,2]. Nuclear reactions and elastic scattering are the more precise nuclear techniques for obtaining absolute values of concentrations in surface analysis. Nuclear reactions provide, not only high sensitivities for detection of light elements in heavy substrates, but also discrimination of isotopes. We consider the "energy analysis method", where a spectrum is acquired of ions from the target for a single energy of an incident ion beam. The spectrum inherently contains target composition and concentration profile information. A computational procedure has been developed for predicting such energy spectra, where elastic scattering is a particular and important case [3]. The model mainly accounts for: target parameters, such as composition and concentration profiles; energy spread of the incident ion beam; geometric factors and target rotation; stopping power; differential cross section; energy straggling; detector resolution. An option permits inclusion of effects such as: multiple scattering; incident beam size and angular divergence; detector angular aperture. Computer simulated spectra are compared to experimental data. The chi-square is calculated, to evaluate the goodness of fit. Through variation of target parameters, so as to fit experimental data, target composition and concentration profiles are obtained.

Microscopy was used for observation of surface topography (Fig. 1-A,B). Depth distributions of light ${ }^{12} \mathrm{C},{ }^{16} \mathrm{O}$ and ${ }^{18} \mathrm{O}$ isotopes were found through $(\mathrm{d}, \mathrm{p}),(\mathrm{d}, \mathrm{p})$ and $(\mathrm{d}, \alpha),(\mathrm{p}, \alpha)$ reactions for several flat targets at $165^{\circ}$ and $135^{\circ}$ detection angles: pyrolitic graphite $(C)$, quartz and a steel target which was sequentially oxidised at $750{ }^{\circ} \mathrm{C}$ first in $\mathrm{C}^{16} \mathrm{O}_{2}$ for $36 \mathrm{~h}$ and then in $\mathrm{C}^{18} \mathrm{O}_{2}$ for $40 \mathrm{~h}(L 3)$. $\mathrm{X}_{\mathrm{i}}$ is a target or target layer thickness parameter. $E_{d}$ and $E_{p}$ are bombarding energies for deuteron and proton beams, respectively. Available data were used for differential cross sections and stopping powers. Measured differential cross section data were considered for the ${ }^{12} \mathrm{C}\left(\mathrm{d}, \mathrm{p}_{0}\right){ }^{13} \mathrm{C}$ reaction [4]. The main results for ${ }^{12} \mathrm{C}$ and ${ }^{18} \mathrm{O}$ consisted in finding: a step concentration profile of ${ }^{12} \mathrm{C}$ through the ${ }^{12} \mathrm{C}\left(\mathrm{d}, \mathrm{p}_{0}\right){ }^{13} \mathrm{C}$ reaction (Fig. 1-C); a complementary error function (erfc) profile of ${ }^{18} \mathrm{O}$ due to diffusion, through the ${ }^{18} \mathrm{O}\left(\mathrm{p}, \alpha_{0}\right){ }^{15} \mathrm{~N}$ reaction (Fig. 1-D). For the quartz target we found: a thin surface film of ${ }^{12} \mathrm{C}$ with uniform concentration and thickness $\mathrm{X}_{1}=0.062 \mu \mathrm{m}$; a uniform ${ }^{16} \mathrm{O}$ distribution in the quartz whose thickness parameters $X_{2}$ varied from 3.4 to $5.5 \mu \mathrm{m}$, depending on the reaction in ${ }^{16} \mathrm{O}$ (Fig.1-E). Elastic scattering of $\alpha$ particles was used for analysing a flat target consisting of a thin film of $\mathrm{Ag}$ deposited on a thick Al substrate $(\mathrm{Al} / \mathrm{Ag})$. An Ag film with excellent uniformity and thickness $\mathrm{X}_{1}=0.1625 \mu \mathrm{m}$ was found (Fig. 1-F).

Successful and important answers were obtained in problem areas of surface analysis by nuclear reactions, for depth profiling of ${ }^{12} \mathrm{C},{ }^{16} \mathrm{O}$ and ${ }^{18} \mathrm{O}$ nuclei, and elastic scattering. The computer simulated spectra for nuclear reactions and elastic scattering, have given good descriptions of experimental spectra obtained for thick samples and considerable depths close to the surface, and for samples containing thin films. While scanning electron microscopy was used as a 
complementary technique to check surface topography, the nuclear techniques have shown to be very powerful analytical tools permitting to find depth profiles of light isotopes and elements. Most of the results here presented would be very difficult to obtain by non-nuclear techniques.

\section{References}

[1] J. M. Calvert, D. J. Derry, D. G. Lees, J. Phys. D: Appl. Phys. 7 (1974) 940.

[2] G. Amsel, G. Battistig, Nucl. Instr. and Meth. B 240 (2005) 1.

[3] J. A. R. Pacheco de Carvalho, Ph. D. Thesis, University of Manchester, England, 1984.

[4] J. A. R. Pacheco de Carvalho, A. D. Reis, 9th European Conference on Accelerators in Applied Research and Technology, Florence-Italy, 3-7 September 2007, p. 100.
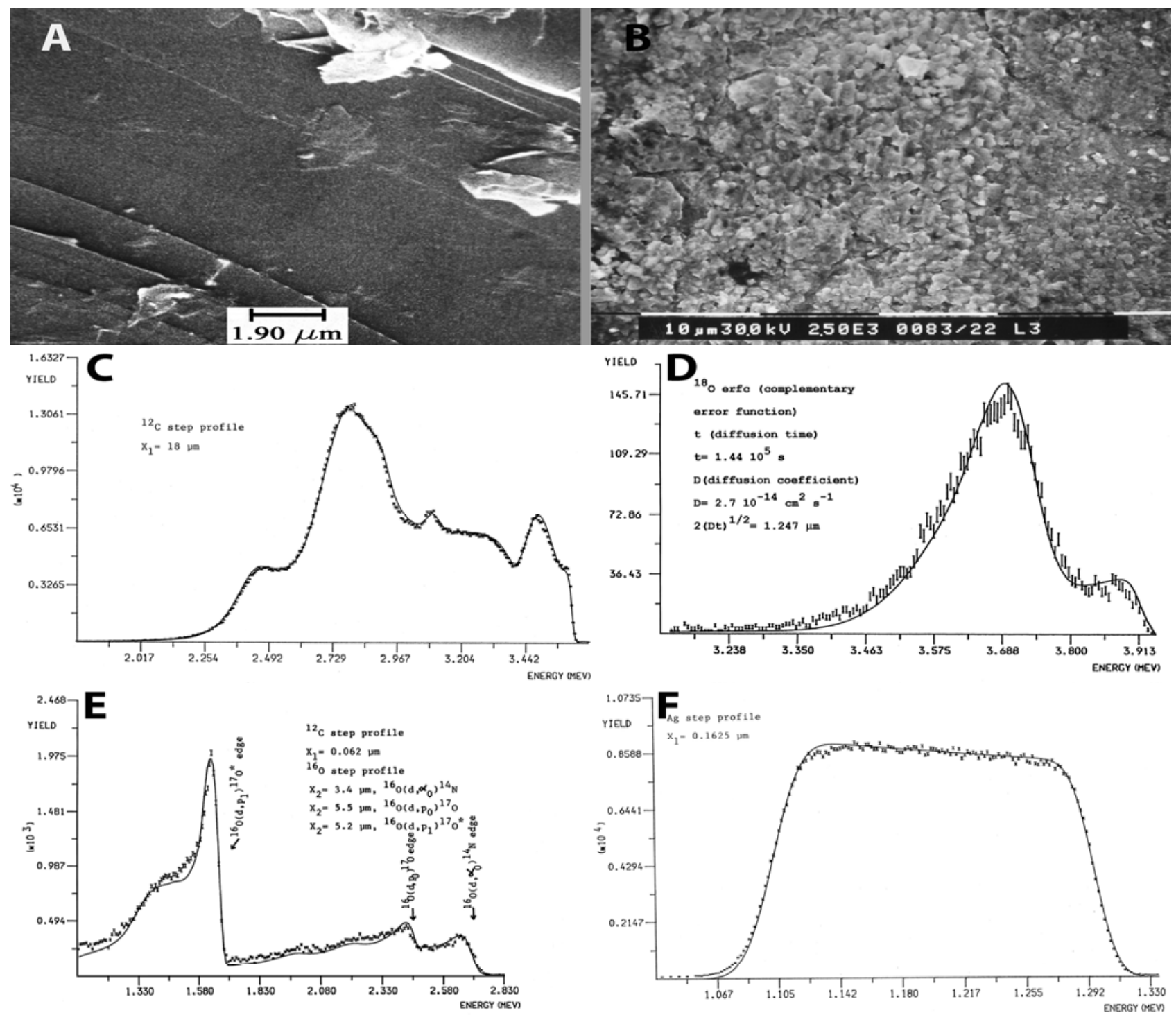

Fig. 1. SEM pictures and computed fits to energy spectra. A. Pyrolitic graphite target (C). B. Sequentially oxidized steel alloy (L3). C. ${ }^{12} \mathrm{C}\left(\mathrm{d}, \mathrm{p}_{0}\right){ }^{13} \mathrm{C}$ reaction in the $\mathrm{C}$ target, $\mathrm{E}_{\mathrm{d}}=1.86 \mathrm{MeV}$, $135^{\circ}$. D. ${ }^{18} \mathrm{O}\left(\mathrm{p}, \alpha_{0}\right){ }^{15} \mathrm{~N}$ reaction in target $\mathrm{L} 3, \mathrm{E}_{\mathrm{p}}=1.78 \mathrm{MeV}, 165^{\circ}$. E. $(\mathrm{d}, \mathrm{p})$ and $(\mathrm{d}, \alpha)$ reactions in the quartz target, $\mathrm{E}_{\mathrm{d}}=1.0 \mathrm{MeV}, 135^{\circ}$. F. Elastic scattering for the $\mathrm{Al} / \mathrm{Ag}$ target, $\mathrm{E}_{\alpha}=1.5 \mathrm{MeV}, 165^{\circ}$. 